\title{
Direct and indirect effects of functional and dysfunctional impulsivity on sensation seeking in youth (19-25 years old)
}

\author{
Stanislava Stoyanova ${ }^{\mathrm{a} *}$, Nikolay Ivantchev ${ }^{\mathrm{a}}$ \\ ${ }^{a}$ Department of Psychology, South-West University "Neofit Rilski”, Blagoevgrad 2700,
}

\begin{abstract}
This study was focused on the relationships between sensation seeking, functional and dysfunctional impulsivity in youth. The aim of this study was to investigate the direct and indirect effects of functional and dysfunctional impulsivity on sensation seeking in youth controlled for gender and age in the group of 19-25-year-old. Radoslavova \& Velichkov's (2005) self-report paper-and-pencil questionnaire was used to measure sensation seeking, functional and dysfunctional types of impulsivity among 764 students. Dysfunctional impulsivity was directly and indirectly related to sensation seeking mediated by functional impulsivity and being statistically controlled for age and gender. Functional impulsivity also was directly and indirectly related to sensation seeking mediated by dysfunctional impulsivity with gender and age as controlled confound variables. Dysfunctional impulsivity had larger direct and indirect effects as a mediator on sensation seeking than the corresponding effects of functional impulsivity on sensation seeking controlling for age and gender. These findings suggest the possibility for existence of some deficiencies in the speed, accuracy, and effectiveness of processing information, making decisions, and implementing actions during the search for optimal stimulation among youth.
\end{abstract}

Keywords: dysfunctional impulsivity; functional impulsivity; sensation seeking; youth

\section{Introduction}

It is important to study impulsivity because it influences on the speed and accuracy of processing information, as well as on the effectiveness of made decisions and implemented actions (Dickman, 1990). Impulsivity is a personality trait (Netto et al., 2016; Steele, Pirkle, \& Kirkpatrick, 2017; Wang, Tao, Fan, Gao, \& Wei, 2017) expressing some normal individual and group differences, according to such social and demographic characteristics as, for example, specialty (Stoyanova \& Giannouli, 2018) or size of place of living (Giannouli \& Stoyanova, 2019).

Impulsivity is related to some others personality traits. Hysterical personality traits are related to impulsiveness (Schalling \& Åsberg, 1985). Extraversion includes impulsivity and sociability (Eysenck, 1987; Schalling, \& Åsberg, 1985). Impulsivity as a part of Extraversion is called also solidity, and high impulsivity means low solidity (Schalling \& Åsberg, 1985). Impulsivity is a part of Psychotism (Ahn \& Vassileva, 2016; Radoslavova \& Velichkov, 2005), together with sensation seeking (Radoslavova \& Velichkov, 2005). Sensation-seeking is a personality trait that includes the desire to pursue novel, intense and adventurous experiences, even if risks are involved, and disliking dull or repetitive activities (Cross, Cyrenne, \& Brown, 2013).

The literature review reveals the existence of some controversial theoretical stances regarding the connection between impulsivity and sensation seeking. According to one viewpoint, sensation-seeking is a reward-sensitive (Zhao et al., 2017) component of impulsivity (Popov et al., 2016; Whiteside \& Lynam, 2001) together with positive

* Corresponding author.

E-mail address: avka@swu.bg

DOI: $10.51865 / J E S P .2021 .1 .15$ 
urgency and negative urgency (two parts of the emotion-based disposition to engage in rash actions), lack of premeditation/planning, and lack of perseverance - deficits in conscientiousness to act without forethought or to tolerate a boredom task (Lynam, n.d.; Reas, Pedersen, \& Rø, 2016; Whiteside \& Lynam, 2001; Zhao et al., 2017). However, some other scientists (Radoslavova \& Velichkov, 2005; Zuckerman, Kolin, Price, \& Zoob, 1964) consider sensation seeking and impulsivity as connected, but different phenomena that should be studied independently of each other.

Some authors (Kumar \& Singh, 2015; Miller, 2007; Zuckerman, 2007) use the more recent term Impulsive sensation seeking to outline the links between impulsivity and sensation seeking. Impulsive sensation seeking is a multidimensional dimension of personality with two aspects - impulsivity and sensation seeking (Zuckerman, 2007) or lack of premeditation and sensation seeking (Miller, 2007). That is Miller (2007) relates lack of premediation to impulsivity.

Impulsive sensation seeking may be expressed as taking more financial, health/safety and social risk (Kumar \& Singh, 2015). Impulsive sensation seekers are prone to psychoticism and overcoming bans, arrogant, non-conformist, and unconventional, intolerant to boredom, experience seeking, with inadequate planning skills, not considering the probable negative consequences from risk (Taneva, 2012). Some other authors state that increased impulsive behaviours are associated with risk (Ahn \& Vassileva, 2016), especially with a greater prevalence of sexual risk behaviour (Netto et al., 2016), without including sensation seeking in the relationship between impulsivity and risk-taking. However, it has been established that sensation seeking is a predictor of risky behavior in the areas of criminal behavior and social violations (Horvath \& Zuckerman, 1993). Sensation seeking, urgency, and lack of premeditation are related to riskier driving (Bachoo, Bhagwanjee, \& Govender, 2013).

In addition, it has been established that impulsiveness is not related to thrill and adventure seeking, and impulsivity weakly correlates with disinhibition (Manna, Faraci, \& Como, 2013), i.e. with seeking of sensation through drinking, partying, and a variety of sexual behaviours (Leung, 2008; Zuckerman, 2005). Some authors specify that sensation seeking correlates with functional and dysfunctional impulsivity (Radoslavova \& Velichkov, 2005).

Functional and dysfunctional impulsivity differ in accuracy of information processing (Zadravec, Bucik, \& Sočan, 2005). Functional impulsivity is the tendency to make quick effective decisions (Pitts \& Leventhal, 2012), acting fast with little forethought, but with positive outcomes (Dickman, 1990; Zadravec, Bucik, \& Sočan, 2005). Functional impulsivity correlates with extraversion (Zadravec, Bucik, \& Sočan, 2005). Dysfunctional impulsivity is the propencity to make quick ineffective decisions (Pitts \& Leventhal, 2012) creating hardship, because of acting with less forethought (Dickman, 1990) not considering the outcomes (Zadravec, Bucik, \& Sočan, 2005). Dysfunctional impulsivity correlates to psychoticism (Zadravec, Bucik, \& Sočan, 2005), as impulsive sensation seeking does (Taneva, 2012). Functional and dysfunctional impulsivity are not highly correlated (Dickman, 1990).

Impulsivity includes also Attentional impulsiveness - focusing on the task at hand, thought insertions and racing thoughts; Motor impulsiveness - acting without thinking; Nonplanning impulsiveness - orientation towards present, the lack of future directedness; and Cognitive impulsiveness - making quick cognitive decisions (Patton, Stanford, \& Barratt, 1995). Cognitive impulsiveness has not been supported empirically, but it has been found that impulsiveness correlates with timing and rhythm characteristics of cognition and performance (Patton, Stanford, \& Barratt, 1995). Impulsivity is not a unitary construct (Maraz et al., 2016), but it is a multifaceted construct (Evren \& Bozkurt, 2017; Netto et al., 2016).

The relationships between the different types of impulsivity and social norms are not uni-directed. In relation to smoking, for example, dysfunctional impulsivity is associated with more difficulties in refraining from smoking in forbidden places, and craving, but functional impulsivity is inversely associated with cigarette craving, i.e. functional impulsivity is not related with increased smoking behaviour and it may associate with reduced drive to smoke (Pitts \& Leventhal, 2012). The smokers with 
schizophrenia have higher impulsivity than non-smokers with schizophrenia (Kao, Liu, Cheng, \& Chou, 2011). The people suffering from some diseases typically tend to be more impulsive (Ahn \& Vassileva, 2016; Dervic et al., 2015; Evren \& Bozkurt, 2017; Maraz et al., 2016; Netto et al., 2016; Reas, Pedersen, \& R $\varnothing, 2016$; Steele, Pirkle, \& Kirkpatrick, 2017; Tamam, Paltaci, \& Keskin, 2017; Zhao et al., 2017), but there are some exceptions, as people with oncological diseases manifest low impulsivity (Manova, 2014).

Low impulsivity means high self-control (Hosu, \& Nastasa, 2008) and good emotion regulation (Yıldız \& Gündüz, 2020), but impulsivity does not have only negative consequences (Netto et al., 2016). There are some positive outcomes from impulsivity such that impulsivity may encourage orientation towards hedonistic experiences (Slavchov \& Virmozelova 2007) that explains partly the connection found between impulsivity and buying behaviour (Jung, 2017), proneness for business start and enterprising activities (Kazandzhieva, 2014).

It is substantial to explore the relatedness between sensation seeking, functional and dysfunctional impulsivity to elucidate the appropriateness of ways for seeking optimal stimulation and the effectiveness of outcomes from sensation seeking. Establishing the strength of connections between different types of impulsivity and sensation seeking would reveal if the most appropriate ways were applied in search for optimal stimulation in case of stronger link between sensation seeking and functional impulsivity than weaker relatedness between sensation seeking and dysfunctional impulsivity. The direct and indirect effects of functional and dysfunctional impulsivity on sensation seeking have been analysed in two mediation models without control for the effect of any confounding variables and larger direct and mediating effects of dysfunctional impulsivity were found (Stoyanova \& Ivantchev, 2021).

One hypothesis of present research stated that dysfunctional impulsivity would be directly related to sensation seeking, as well as indirectly related to sensation seeking mediated by functional impulsivity and controlled for gender and age from 19 to 25 years old to minimize spurious associations between these variables. Another hypothesis stated that functional impulsivity would be directly related to sensation seeking, as well as indirectly related to sensation seeking mediated by dysfunctional impulsivity and controlled for gender and age from 19 to 25 years old to minimize false associations between these variables. The hypotheses are based on the established relatedness between impulsivity and sensation seeking by Kumar \& Singh (2015), Miller (2007), Popov et al. (2016), Radoslavova \& Velichkov (2005), Stoyanova \& Ivantchev (2021), Whiteside \& Lynam (2001), Zuckerman (2007), Zuckerman, Kolin, Price, \& Zoob (1964), as well as on some age periodizations postulating the presence of common features for the youth age (Augustus-Horvath \& Tylka, 2011; Nikolov, Georgiev, \& Madolev, 2007) and on research findings regarding the effect of gender on impulsivity indicating that men were more prone to dysfunctional impulsivity than women (Cross et al., 2011). However, another study (Stoyanova \& Giannouli, 2018) did not differentiate male and female students in their impulsivity, neither found age effects on impulsivity from 20 to 30 years old, but any sub-types of impulsivity were not studied. The previous research has not specified which type of impulsivity is more closely related to sensation seeking in the group of youth from 19 to 25 years old controlling for age and gender as confounding variables. Another study has used the same approach to include a set of variables in several (three) mediation models to be proposed the best mediation model among them (Maidaniuc-Chirila \& Treadway, 2016).

\section{Methodology}

\subsection{Study design and procedure}

A cross-sectional study was conducted in 2018-2019 academic year in several Bulgarian universities, as the sample was purposefully selected to consists of youth. Children are up to 18 years old (Convention on the Rights of the Child, 1990). Youth age range is within 18 and 25 years old (Augustus-Horvath \& Tylka, 2011; Nikolov, 
Georgiev, \& Madolev, 2007, p.90). Early adulthood varies between 21 and 25 years old (Anan'ev, 2001, pp. 112-115). Most students are part of the age group of youth, and they were invited to take part in the study. Their participation was voluntarily and anonymously.

\subsection{Participants}

Seven hundred and sixty-four university students were studied by means of a selfreport questionnaire. It has been found that an individual's perception of his/her own efficiency is a cognitive mediator of human acts (Azar \& Mahmoudi, 2014) that reveals the importance of self-assessment of own qualities, skills, and abilities.

The participants' social and demographic characteristics are presented in Table 1. Their age was normally distributed (skewness $=0.267$, kurtosis $=-0.404$ ) and varied from 19 to 25 years old with mean age 21.35 years, and $S D=1.43$ years. The female students prevailed $\left(\chi^{2}(1, N=764)=72.901, p<.001\right.$, expected count for both genders was 382), as well as the students in their $3^{\text {rd }}$ year of study $\left(\chi^{2}(3, N=764)=27.466, p<\right.$ .001 , expected count for each years of study was 191), from the scientific area of social sciences and humanities $\left(\chi^{2}(6, N=764)=343.649, p<.001\right.$, expected count for each scientific area was 109), with medium income $\left(\chi^{2}(2, N=764)=126.223, p<.001\right.$, expected count for each level of income was 255), living in the cities above 50,000 inhabitants $\left(\chi^{2}(4, N=764)=353.683, p<.001\right.$, expected count for each type of place of living was 153; see Table 1). They were from different geographic areas of Bulgaria, mainly from the regions of South-West Bulgaria - Blagoevgrad $(N=218)$, Sofia $(N=$ $124)$, Kyustendil $(N=52)$, Pernik $(N=21)$; North-West Bulgaria - Vratsa $(N=41)$, Pleven $(N=25)$, Vidin $(N=21)$; Central part of Bulgaria - Plovdiv $(N=35)$, Pazardzhik $(N=29)$, Haskovo $(N=10)$, Smolyan $(N=10)$, and some other regions in Bulgaria.

Table 1. Social and demographic characteristics of the participating youth

\begin{tabular}{cccc}
\hline Social category & Sub-group & $N$ & $\%$ \\
\hline \multirow{2}{*}{ Gender } & Male & 264 & 34.555 \\
& Female & 500 & 65.445 \\
& & 148 & 19.372 \\
Year of study & $1^{\text {st }}$ year of study & 189 & 24.738 \\
& $2^{\text {nd }}$ year of study & 248 & 32.461 \\
3 $^{\text {rd }}$ year of study & 179 & 23.429 \\
$4^{\text {th }}$ year of study & & \\
Income & Low income & 185 & 24.215 \\
& Medium income & 401 & 52.487 \\
Type of place of living & High income & 178 & 23.298 \\
in dependence on the & & & \\
size and density of & Village & 103 & 13.482 \\
population & Town & 172 & 22.513 \\
& City & 344 & 45.026 \\
& Capital & 102 & 13.351 \\
& Bulgarians living abroad & 43 & 5.628 \\
& Arts & 65 & 8.508 \\
Scientific areas & Social sciences and humanities & 282 & 36.912 \\
& Economy & 64 & 8.377 \\
& Education & 51 & 6.675 \\
& Sport & 106 & 13.874 \\
& Medical care & 99 & 12.958 \\
& Technical sciences & 97 & 12.696 \\
\hline
\end{tabular}




\subsection{Instrument}

Radoslavova and Velichkov's (2005) paper-and-pencil questionnaire based on Zuckerman, Kolin, Price and Zoob's (1964) ideas, as well as on Dickman's (1990) ideas, was applied for measurement of sensation seeking, functional impulsivity and dysfunctional impulsivity. Its scale of sensation seeking includes 24 dichotomous items (for example, item 38 "I like doing things that are somewhat dangerous", and item 74 "I tend to try every new thing at least once") with Cronbach's alpha of .80 (Radoslavova \& Velichkov, 2005, pp.11-20). Radoslavova and Velichkov's scale of functional impulsivity consists of 10 dichotomous items (for example, item 30 "I like games and sports in which the moves or movements must be chosen in a flash", and item 48 "I like to engage in dynamic conversations where there is no time to think in advance what to say") with Cronbach's alpha of .75 (Radoslavova \& Velichkov, 2005, pp.11-20). Radoslavova and Velichkov's scale of dysfunctional impulsivity comprises 18 dichotomous items (for example, item 63 "I often get in trouble because I do not think about what I am doing", and item 77 "I am a hurried person") with Cronbach's alpha of .81 (Radoslavova \& Velichkov, 2005, pp.11-20). Their possible answers are "Yes" or "No". This questionnaire also contains 27 neutral items (such as item 9 "My thoughts often jump from question to question without being able to focus on something specific") intended to hide the real goal of measurement and not being included in any scale (Radoslavova \& Velichkov, 2005).

\subsection{Data analysis}

Data collected in this study is made available in Mendeley public data repository (Stoyanova, 2020). Statistical power (sensitivity, according to Glen, 2015) was computed by means of the software GPower 3.1.9.2 (Faul, Erdfelder, Lang, \& Buchner, 2007). Data was analyzed by means of SPSS 20.0 (IBM Corp., 2011) applying descriptive statistics for establishing the frequency distribution of functional impulsivity, dysfunctional impulsivity, and sensation seeking; Pearson bivariation and partial correlations using bootstrapping procedure with 5000 sub-samples of data and linear regression analysis for examining the connections between these variables; multinomial chi-squared analysis for establishing the equality of some socialdemographic groups, and especially male and female participants, because gender was regarded as a potential confounding variable. Mediation analysis using bootstrapping procedure with 5000 sub-samples of data and maximum-likelihood method was applied with the software JASP 0.11.1.0 (JASP Team, 2019). The data was processed with bootstrapping for mediation analysis that was recommended by Fairchild \& McQuillin (2010), MacKinnon, Fairchild, \& Fritz, (2007), Zarbova (2019) as not requiring normal distribution (Zarbova, 2019), neither supposing any distributional assumptions (Preacher \& Leonardelli, 2001).

A variable on nominal level of measurement as gender (with two possible values coded as 0 and 1 , as recommended by Hayes, 2017) was included in the mediation models as a covariate, i.e., confounding variable. Confounding association means that the connection between some variables could be attributed to a third variable that may affect all the associations between the other variables in a mediation model (Hayes, 2017). The covariates of age and gender were statistically controlled in the estimation of the direct, indirect and total effects in two mediation models of relationships between functional, dysfunctional impulsivity and sensation seeking.

\section{Results}

Table 2 presents the mean scores on the scales of Sensation seeking, Functional impulsivity, and Dysfunctional impulsivity, as well as check of normality distribution of the scores on these scales. Statistical power (sensitivity, according to Glen, 2015) was above 0.95 for these three studied variables and it was calculated by means of the software GPower 3.1.9.2 (Faul, Erdfelder, Lang, \& Buchner, 2007) comparing the 
means of the sample in the current study to the means of the sample in the study by Radoslavova \& Velichkov (2005) when the questionnaire was created and validated.

Table 2. Mean scores, standard deviations, coefficients of skewness and kurtosis on the scales of Sensation seeking, Functional impulsivity, and Dysfunctional impulsivity

\begin{tabular}{cccc}
\hline & $\begin{array}{c}\text { Functional } \\
\text { impulsivity }\end{array}$ & $\begin{array}{c}\text { Dysfunctional } \\
\text { impulsivity }\end{array}$ & Sensation seeking \\
\hline Mean & 5.683 & 8.440 & 13.736 \\
Standard Deviation & 1.976 & 3.920 & 4.639 \\
Skewness & -0.287 & -0.107 & -0.530 \\
Kurtosis & -0.119 & -0.695 & -0.237 \\
\hline
\end{tabular}

The coefficients of skewness and kurtosis of test scores on three scales varied between -1 and +1 (see Table 2), i. e. the distribution of test scores approximated the normal distribution (Hair, Hult, Ringle, \& Sarstedt, 2016, p.54).

Increase of sensation seeking was related to increase in dysfunctional impulsivity $(r$ $=0.409 ; p<.001 ; N=764 ; 95 \%$ bias corrected accelerated bootstrapped confidence intervals varied berween 0.347 and 0.469$)$ and increase in functional impulsivity ( $r=$ $0.387 ; p<.001 ; N=764 ; 95 \%$ bias corrected accelerated bootstrapped confidence intervals varied berween 0.321 and 0.451 ). Increase of functional impulsivity was related to small increase in dysfunctional impulsivity $(r=0.271 ; p<.001 ; N=764$; $95 \%$ bias corrected accelerated bootstrapped confidence intervals varied berween 0.205 and 0.338). Statistical power (sensitivity, according to Glen, 2015) was above 0.95 for the correlations between sensation seeking, functional and dysfunctional impulsivity.

Mediation analysis with predictor functional impulsivity, mediator dysfunctional impulsivity, outcome variable sensation seeking, and two confound variables - age and gender, specified the relationships between these variables - see Table 3, Table 4, Table 5 and Fig. 1.

Table 3. Direct effects of functional impulsivity on sensation seeking covariated by age and gender

\begin{tabular}{lccccccc} 
Predictor & Outcome & Estimate & $\begin{array}{c}\text { Standard } \\
\text { error }\end{array}$ & & $z$-value & $p$ & \multicolumn{2}{c}{$\begin{array}{c}95 \% \text { bias - } \\
\text { corrected } \\
\text { bootstrap } \\
\text { confidence } \\
\text { interval }\end{array}$} \\
& & & & & & \multicolumn{3}{c}{$\begin{array}{c}\text { Lower } \\
\text { Upper }\end{array}$} \\
\hline $\begin{array}{l}\text { Functional } \\
\text { impulsivity }\end{array}$ & $-\begin{array}{c}\text { Sensation } \\
\text { seeking }\end{array}$ & 0.298 & 0.033 & 9.158 & $<.001$ & 0.230 & 0.364 \\
\hline
\end{tabular}

Functional impulsivity directly and positively influenced on sensation seeking, so increase in functional impulsivity augmented sensation seeking statistically controlling for age and gender (see Table 3 ).

Table 4. Indirect effects of functional impulsivity on sensation seeking mediated by dysfunctional impulsivity, and covariated by age and gender

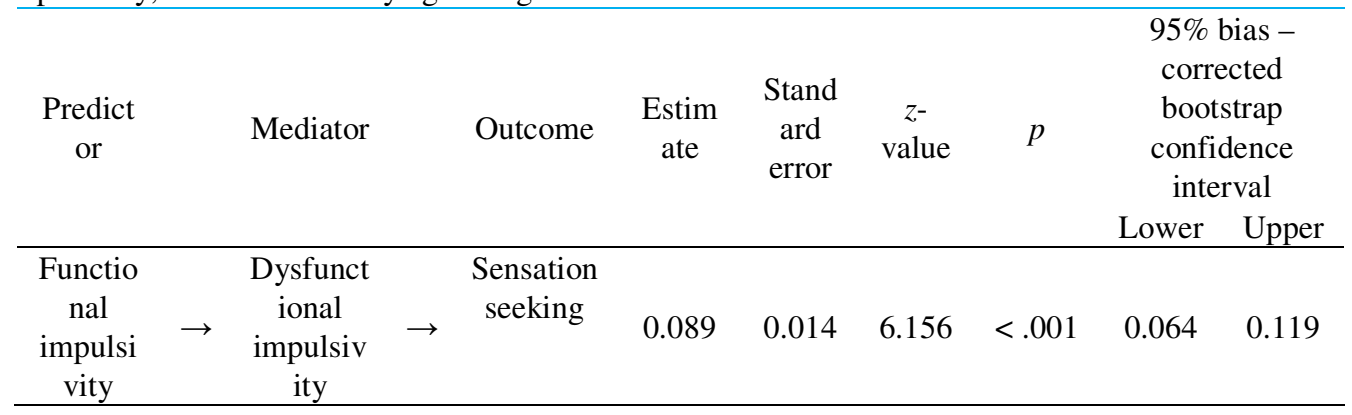


Functional impulsivity influenced indirectly and positively on sensation seeking mediated by dysfunctional impulsivity, so increase of functional impulsivity augmented dysfunctional impulsivity that increased also sensation seeking statistically controlling for age and gender (see Table 4 and Fig. 1).

Table 5. Total effects of functional impulsivity on sensation seeking covariated by age and gender

\begin{tabular}{|c|c|c|c|c|c|c|c|c|}
\hline \multirow[t]{2}{*}{ Predictor } & & \multirow[t]{2}{*}{ Outcome } & \multirow[t]{2}{*}{ Estimate } & \multirow[t]{2}{*}{$\begin{array}{c}\text { Standard } \\
\text { error }\end{array}$} & \multirow[t]{2}{*}{$z$-value } & \multirow[t]{2}{*}{$p$} & \multicolumn{2}{|c|}{$\begin{array}{c}95 \% \text { bias - } \\
\text { corrected } \\
\text { bootstrap } \\
\text { confidence } \\
\text { interval }\end{array}$} \\
\hline & & & & & & & Lower & Lower \\
\hline $\begin{array}{l}\text { Functional } \\
\text { impulsivity }\end{array}$ & $\rightarrow$ & $\begin{array}{c}\text { Sensation } \\
\text { seeking }\end{array}$ & 0.387 & 0.033 & 11.602 & $<.001$ & 0.315 & 0.458 \\
\hline
\end{tabular}

Total effects include combination of direct and indirect effects. Increase in functional impulsivity augmented sensation seeking seeking statistically controlling for age and gender - see Table 5 and Fig. 1. Coefficient of determination for change in sensation seeking was $R^{2}=0.250$, i. e., the model explained $25 \%$ of variance (Zarbova 2019) in change of sensation seeking that was medium effect size (Awang, 2015, p.105). Coefficient of determination for change in dysfunctional impulsivity was $R^{2}=$ 0.085 , i. e., the model explained $8.5 \%$ of variance (Zarbova 2019) in change of dysfunctional impulsivity that was small effect size (Awang, 2015, p.105). Increase in functional impulsivity augmented sensation seeking and dysfunctional impulsivity statistically controlling for age and gender. Increase in dysfunctional impulsivity augmented sensation seeking statistically controlling for age and gender.

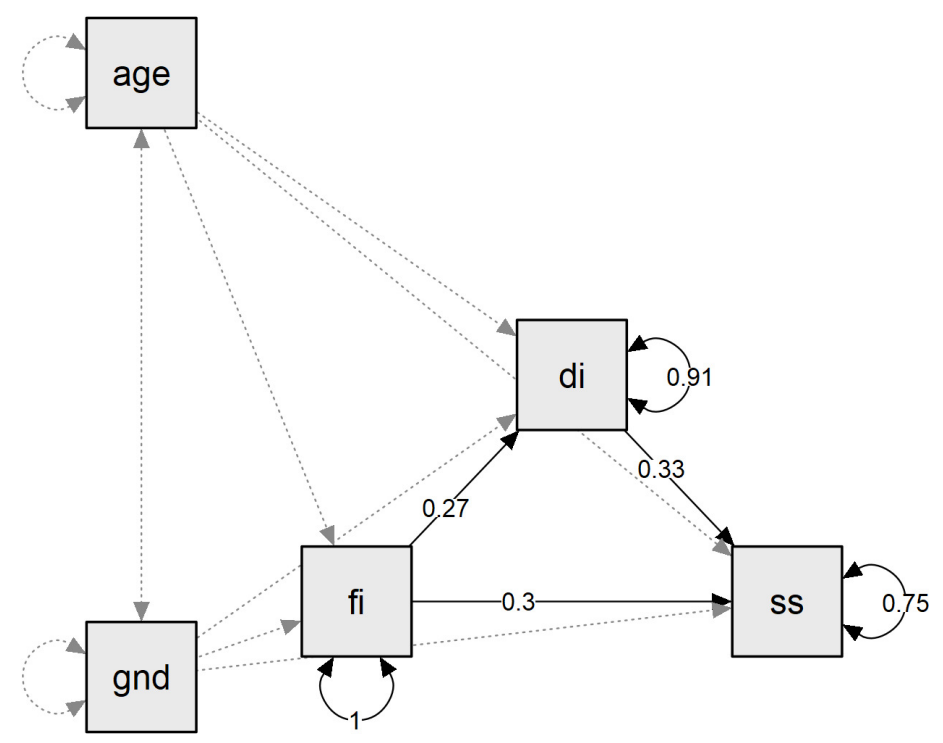

Fig. 1. Direct and indirect effects of functional impulsivity on sensation seeking mediated by dysfunctional impulsivity statistically controlling for age and gender

Note: fi means functional impulsivity, di means dysfunctional impulsivity, ss means sensation seeking, gnd means gender

Mediation analysis with predictor dysfunctional impulsivity, mediator functional impulsivity, outcome variable sensation seeking and confounding variables age and gender specified the relationships between these variables - see Table 6, Table 7, Table 8, and Figure 2. 
Table 6. Direct effects of dysfunctional impulsivity on sensation seeking covariated by age and gender

\begin{tabular}{|c|c|c|c|c|c|c|c|c|}
\hline \multirow[t]{2}{*}{ Predictor } & & \multirow[t]{2}{*}{ Outcome } & \multirow[t]{2}{*}{ Estimate } & \multirow[t]{2}{*}{$\begin{array}{l}\text { Standard } \\
\text { error }\end{array}$} & \multirow[t]{2}{*}{$z$-value } & \multirow[t]{2}{*}{$p$} & \multicolumn{2}{|c|}{$\begin{array}{c}95 \% \text { bias - } \\
\text { corrected } \\
\text { bootstrap } \\
\text { confidence } \\
\text { interval }\end{array}$} \\
\hline & & & & & & & Lower & Upper \\
\hline $\begin{array}{c}\text { Dysfunctional } \\
\text { impulsivity }\end{array}$ & $\rightarrow$ & $\begin{array}{c}\text { Sensation } \\
\text { seeking }\end{array}$ & 0.329 & 0.033 & 10.060 & $<.001$ & 0.265 & 0.392 \\
\hline
\end{tabular}

Dysfunctional impulsivity and positively directly influenced on sensation seeking, so increase in dysfunctional impulsivity augmented sensation seeking statistically controlling for age and gender (see Table 6).

Table 7. Indirect effects of dysfunctional impulsivity on sensation seeking mediated by functional impulsivity covariated by age and gender

\begin{tabular}{|c|c|c|c|c|c|c|c|c|c|c|}
\hline \multirow[t]{2}{*}{ Predictor } & & \multirow[t]{2}{*}{$\begin{array}{l}\text { Medi } \\
\text { ator }\end{array}$} & & \multirow[t]{2}{*}{ Outcome } & \multirow[t]{2}{*}{$\begin{array}{c}\text { Estima } \\
\text { te }\end{array}$} & \multirow[t]{2}{*}{$\begin{array}{l}\text { Stand } \\
\text { ard } \\
\text { error }\end{array}$} & \multirow[t]{2}{*}{$\begin{array}{c}z- \\
\text { value }\end{array}$} & \multirow[t]{2}{*}{$p$} & \multicolumn{2}{|c|}{$\begin{array}{c}95 \% \text { bias - } \\
\text { corrected } \\
\text { bootstrap } \\
\text { confidence } \\
\text { interval }\end{array}$} \\
\hline & & & & & & & & & Lower & Upper \\
\hline $\begin{array}{l}\text { Dysfunct } \\
\text { ional } \\
\text { impulsiv } \\
\text { ity }\end{array}$ & $\rightarrow$ & $\begin{array}{l}\text { Funct } \\
\text { ional } \\
\text { impul } \\
\text { sivity }\end{array}$ & $\rightarrow$ & $\begin{array}{l}\text { Sensation } \\
\text { seeking }\end{array}$ & 0.081 & 0.014 & 5.930 & $<.001$ & 0.055 & 0.112 \\
\hline
\end{tabular}

Dysfunctional impulsivity influenced indirectly and positively on sensation seeking mediated by functional impulsivity, so increase of dysfunctional impulsivity augmented functional impulsivity that increased also sensation seeking seeking statistically controlling for age and gender (see Table 7 and Fig. 2).

Table 8. Total effects of dysfunctional impulsivity on sensation seeking covariated by age and gender

\begin{tabular}{|c|c|c|c|c|c|c|c|c|}
\hline \multirow{2}{*}{\multicolumn{2}{|c|}{ Predictor }} & \multirow[t]{2}{*}{ Outcome } & \multirow[t]{2}{*}{ Estimate } & \multirow[t]{2}{*}{$\begin{array}{c}\text { Standard } \\
\text { error }\end{array}$} & \multirow[t]{2}{*}{$z$-value } & \multirow[t]{2}{*}{$p$} & \multicolumn{2}{|c|}{$\begin{array}{c}95 \% \text { bias - } \\
\text { corrected } \\
\text { bootstrap } \\
\text { confidence } \\
\text { interval }\end{array}$} \\
\hline & & & & & & & Lower & Lower \\
\hline $\begin{array}{c}\text { Dysfunctional } \\
\text { impulsivity }\end{array}$ & $\rightarrow$ & $\begin{array}{c}\text { Sensation } \\
\text { seeking }\end{array}$ & 0.411 & 0.033 & 12.368 & $<.001$ & 0.342 & 0.476 \\
\hline
\end{tabular}

Total effects include combination of direct and indirect effects. Increase in dysfunctional impulsivity augmented sensation seeking statistically controlling for age and gender - see Table 8 and Fig. 2. Coefficient of determination for change in sensation seeking was $R^{2}=0.250$, i. e., the model explained $25 \%$ of variance (Zarbova 2019) in change of sensation seeking that was medium effect size (Awang, 2015, p.105). Coefficient of determination for change in functional impulsivity was $R^{2}=$ 0.075 , i. e., the model explained $7.5 \%$ of variance (Zarbova 2019) in change of functional impulsivity that was small effect size (Awang, 2015, p.105). Increase in functional impulsivity augmented sensation seeking and dysfunctional impulsivity statistically controlling for age and gender. Increase in functional impulsivity augmented sensation seeking statistically controlling for age and gender. 


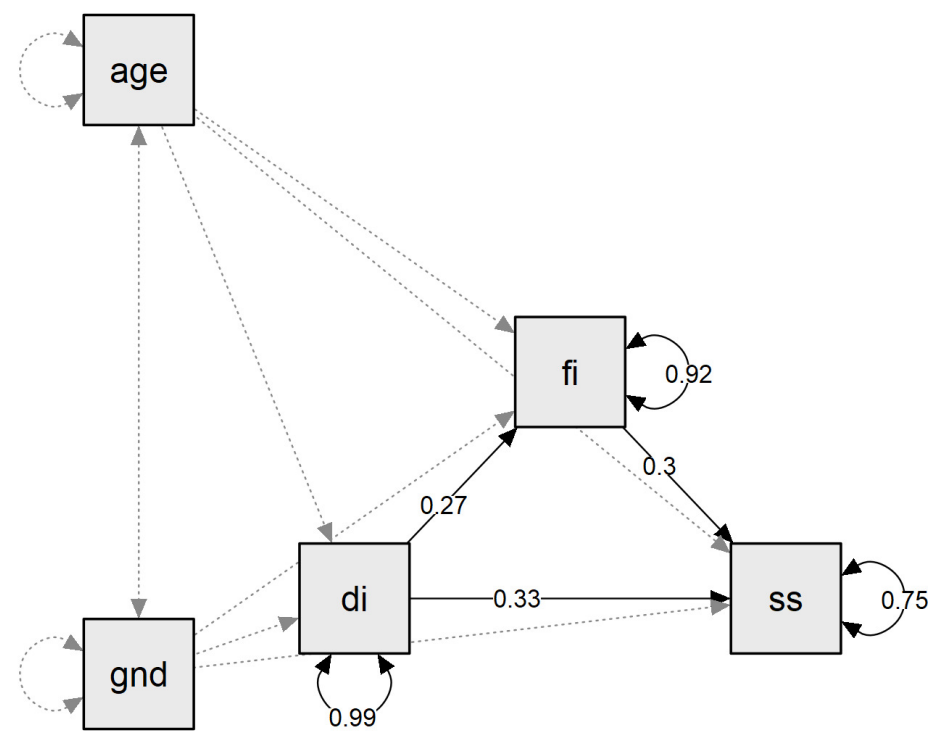

Fig. 2. Direct and indirect effects of dysfunctional impulsivity on sensation seeking mediated by functional impulsivity statistically controlling for age and gender

Note: fi means functional impulsivity, di means dysfunctional impulsivity, ss means sensation seeking, gnd means gender

Mediation analysis established that both models described in Fig. 1 and Fig. 2 explained an equal part of variance of sensation seeking - 25\% each of them. Functional impulsivity (z-value $=9.158$, see Table 3 ) had smaller direct effect on sensation seeking than dysfunctional impulsivity ( $\mathrm{z}$-value $=10.060$, see Table 6) statistically controlling for age and gender. Functional impulsivity (z-value $=6.156$, see Table 4) had stronger indirect effect on sensation seeking than dysfunctional impulsivity (z-value $=5.930$, see Table 7 ) statistically controlling for age and gender. Direct effects of functional and dysfunctional impulsivity on sensation seeking were stronger than their indirect effects statistically controlling for age and gender. Functional impulsivity (z-value $=11.602$, see Table 5) had smaller total effects on sensation seeking than dysfunctional impulsivity ( $\mathrm{z}$-value $=12.368$, see Table 8 ) statistically controlling for age and gender. These findings mean that it could not be stated categorically that the most appropriate ways, neither the least appropriate ways were tried to experience optimal stimulation, because of stronger direct effects of dysfunctional impulsivity on sensation seeking than the direct effects of functional impulsivity on sensation seeking on the one hand statistically controlling for age and gender, but on the other hand there were established stronger indirect and total effects of functional impulsivity on sensation seeking than the indirect and total effects of dysfunctional impulsivity on sensation seeking statistically controlling for age and gender.

The raw correlation for the $a$ path (independent variable - mediator) and the partial correlation for the $b$ path (mediator-dependent variable) are effect size measures for mediation models (MacKinnon, Fairchild, \& Fritz, 2007). For the mediation model in Fig. 1. Direct and indirect effects of functional impulsivity on sensation seeking mediated by dysfunctional impulsivity statistically controlling for age and gender, the raw correlation between the independent variable functional impulsivity and the mediator dysfunctional impulsivity was $r=0.271$, and the partial correlation between the mediator dysfunctional impulsivity and the dependent variable sensation seeking controlled for functional impulsivity, age and gender was $r=0.342, d f=759, p<$ $.001 ; 95 \%$ bias corrected accelerated bootstrapped confidence intervals varied berween 0.278 and 0.402. For the mediation model in Fig. 2. Direct and indirect effects of dysfunctional impulsivity on sensation seeking mediated by functional impulsivity statistically controlling for age and gender, the raw correlation between the 
independent variable dysfunctional impulsivity and the mediator functional impulsivity was $r=0.271$, and the partial correlation between the mediator functional impulsivity and the dependent variable sensation seeking controlled for dysfunctional impulsivity, age and gender was $r=0.315, d f=759, p<.001 ; 95 \%$ bias corrected accelerated bootstrapped confidence intervals varied berween 0.239 and 0.382 . Computed in this way, the first effect size in both mediation models was the same, and the second effect size in these mediation models revealed stronger effect of dysfunctional impulsivity as a mediator on sensation seeking than the effect of functional impulsivity as a mediator of sensation seeking. In this way, it became clear that dysfunctional impulsivity stimulated slightly more sensation seeking than functional impulsivity, i. e., quick ineffective decisions accompanied seeking for optimal stimulation.

Standardized regression coefficients may also be used as effect size measures for individual paths in the mediated effect (MacKinnon, Fairchild, \& Fritz, 2007). Linear regression analysis with independent variable dysfunctional impulsivity and dependent variable sensation seeking was performed $\left(r=0.409 ; \mathrm{r}^{2}=0.168 ; F_{(1.762)}=\right.$ 153.447, $p<.001$, unstandardized coefficient $b=0.485$, standardized coefficient Beta $=0.409, t=12.387, p<.001)$, as well as linear regression analysis with independent variable functional impulsivity and dependent variable sensation seeking was calculated $\left(r=0.387 ; \mathrm{r}^{2}=0.150 ; F(1,762)=134.264, p<.001\right.$, unstandardized coefficient $b=0.909$, standardized coefficient Beta $=0.387, t=11.587, p<.001$ ). Functional impulsivity had smaller direct effect on sensation seeking than dysfunctional impulsivity, because of higher standardized coefficient Beta for dysfunctional impulsivity, as MacKinnon, Fairchild, and Fritz (2007) explained. Dysfunctional impulsivity was more strongly associated with sensation seeking than functional impulsivity.

\section{Discussions}

The findings supported the hypothesis that dysfunctional impulsivity would be directly related to sensation seeking, as well as indirectly related to sensation seeking mediated by functional impulsivity holding gender and age constant to minimize spurious associations between these variables. The results also supported the hypothesis that functional impulsivity would be directly related to sensation seeking, as well as indirectly related to sensation seeking mediated by dysfunctional impulsivity and controlled for gender and age in the group of youth from 19 to 25 years old to minimize false associations between these variables.

Direct positive connections between functional and dysfunctional impulsivity on the one hand and sensation seeking on the other hand statistically controlling for age and gender were established by means of correlation analysis that revealed stronger direct connection between dysfunctional impulsivity and sensation seeking than between functional impulsivity and sensation seeking. Direct positive connections between functional and dysfunctional impulsivity on the one hand and sensation seeking on the other hand statistically controlling for age and gender were also established by means of mediation analysis that revealed stronger direct connection between dysfunctional impulsivity and sensation seeking than between functional impulsivity and sensation seeking statistically controlling for age and gender. Regression analysis indicated that functional impulsivity had smaller direct effects on sensation seeking than dysfunctional impulsivity.

Indirect effects of functional and dysfunctional impulsivity on sensation seeking were weaker than their direct effects controlling for age and gender. Indirect positive connections between functional and dysfunctional impulsivity on the one hand and sensation seeking on the other hand were established by means of mediation analysis that revealed stronger indirect connection between functional impulsivity and sensation seeking than between dysfunctional impulsivity and sensation seeking controlling for age and gender. Partial correlations revealed larger effects of dysfunctional impulsivity as a mediator on sensation seeking than the effects of 
functional impulsivity as a mediator of sensation seeking controlling for age and gender.

Functional impulsivity had smaller total (direct plus indirect) effects on sensation seeking than dysfunctional impulsivity controlling for age and gender. Dysfunctional impulsivity was more strongly connected to sensation seeking, stimulated slightly more sensation seeking than functional impulsivity, i. e., quick ineffective decisions accompanied seeking for optimal stimulation, less appropriate ways were tried to experience optimal stimulation. Dysfunctional impulsivity means proneness to making quick ineffective decisions (Pitts \& Leventhal, 2012), acting without thinking about the outcomes (Zadravec, Bucik, \& Sočan, 2005) that may be due to some attention deficits in case of dysfunctional impulsivity as suggested by Schalling \& Åsberg (1985), Popov et al. (2016), Whiteside \& Lynam (2001), and some difficulties in accuracy and precision of information processing (Schalling \& Åsberg, 1985; Zadravec, Bucik, \& Sočan, 2005). Sensation seeking influenced by dysfunctional impulsivity could have some negative outcomes, for example dysfunctional impulsivity implies more frequent antisocial and deviant behaviour (Kalchev, 2016; Radoslavova \& Velichkov, 2005) and aggression (Radoslavova \& Velichkov, 2005; Raine, Reynolds, Venables, Mednick, \& Farrington, 1998). Relatedness between dysfunctional impulsivity and sensation seeking may partly explain deviant behaviour and attention deficits in youth.

Because of the existence of negative consequences of dysfunctional impulsivity, some various techniques and approaches have been offered to prevent them and overcome impulsivity. Some strategies focused on promoting mental health and encouraging healthful behaviors also aim managing impulsivity (Netto et al., 2016) emphasizing such methods to overcome impulsivity as reward substitution and precommitment (Garza, Ding, Owensby, \& Zizza, 2016). Therapy focusing on mood instability along with impulsivity may be useful (Peters, Balbuena, Marwaha, Baetz, $\&$ Bowen, 2016). Both group narrative therapy and group play therapy are effective in inhibiting impulsivity, and reducing aggression (Kasmaei, \& Asghari, 2017).

Control over impulsivity is exerted by mentalization - understanding own and other people's needs, intentions, thoughts (Mihova, 2014). Because impulsivity correlates positively with alexitimia (Popov et al., 2016), the impulsive people might have some difficulties in processing emotion-related information and recognizing their own emotions that further impede their decision-making and social functioning.

The studies and interventions focused on impulsivity may improve the knowledge about its manifestations and the possibilities to be directed towards more efficient social functioning.

This study had some limitations related to possible social desirability in answering, because of using only a self-report questionnaire. Self-report measures of impulsivity tend to over-estimate impulsivity (Maraz et al., 2016) in research findings. Social desirability includes hyperbolisation of positive self-description and denial of negative self-description that are the most weakly expressed in Bulgarian students compared to other students from 20 countries (He et al., 2015, p.227, p.236) that is why sincere answers may be expected in our sample of Bulgarian students. The results were checked applying several statistical tests - correlation analysis, regression analysis, and mediation analysis, to estimate the relationships between the studied variables more precisely. Controlling the findings for age and gender effects on relationships between sensation seeking, functional and dysfunctional impulsivity also contributed to increasing objectivity of logical inferences from obtained data. Applying more instruments for data collection may further improve objectivity of results.

The findings are limited within the range of the age of the sample (inclusion of youth people only aged from 19 to 25 years old). Besides, only students were studied, and the sample did not include unemployed people between 19 and 25 years old who did not study. The covariates of age and gender were statistically controlled in the estimation of the direct, indirect and total effects in two mediation models of relationships between functional, dysfunctional impulsivity and sensation seeking that, of course, did not eliminate any other potential sources of confounding. Research among more representatives of different social groups would give opportunity for 
generalizing the results or specifying the type of connections between sensation seeking, functional and dysfunctional impulsivity if controlling for more confound variables, including in different age groups. Further cross-cultural studies on the link between impulsivity, its types and sensation seeking may reveal more about its nature while longitudinal studies may contribute to establish the tendencies in its development and manifestations.

\section{Conclusions}

This was the first study that compared the direct and indirect contribution of functional and dysfunctional impulsivity on sensation seeking controlled for such potential confound variables as gender and age from 19 to 25 years old. The findings revealed that sensation seeking as a search for optimal stimulation may be realized by means of some inappropriate ways by young people and may have some negative outcomes (for example, related to functioning, and well-being), because of stronger influence of dysfunctional impulsivity on sensation seeking than the influence of functional impulsivity. The inappropriate ways for sensation seeking due to its relationships with dysfunctional impulsivity might be dangerous for personal health and could impede some social norms. The negative outcomes from sensation seeking influenced by dysfunctional impulsivity may concern personal dissatisfaction, significant others' negative feelings, possible ineffective decisions, personal and professional failures, etc. However, functional impulsivity mediates the effect of dysfunctional impulsivity on sensation seeking that may explain why sensation seeking has also some satisfactory results and enriches personal experience. Future research may further clarify if the above findings regarding the relations between impulsivity and sensation seeking are similar or different in other cultural contexts, in different social groups and may control for other potential confound variables.

\section{References}

1. Ahn, W.-Y., \& Vassileva, J. (2016). Machine-learning identifies substance-specific behavioral markers for opiate and stimulant dependence. Drug \& Alcohol Dependence, 161, 247-257.

2. Anan'ev, B. G. (2001). Chelovek kak predmet poznaniya [Human being as an object of knowledge]. Saint-Peterburg, Rossia: Piter.

3. Augustus-Horvath, C. L. \& Tylka, T. L. (2011). The acceptance model of intuitive eating: A comparison of women in emerging adulthood, early adulthood, and middle adulthood. Journal of Counseling Psychology, 58(1), 110-125.

4. Awang, Z. (2015). Computing the effect size of a mediator. https://www.researchgate.net/publication/276934397_CCOMPUTING_THE_EFFECT_SIZE_ OF_A_MEDIATOR

5. Azar, F. S., \& Mahmoudi, L. (2014). Relationship between Mathematics, self-efficacy and students' performance in statistics: The meditational role of attitude toward Mathematics and Mathematics anxiety. Journal of Educational Sciences \& Psychology, 4(1), 32 - 42.

6. Bachoo, S., Bhagwanjee, A., \& Govender, K. (2013). The influence of anger, impulsivity, sensation seeking and driver attitudes on risky driving behaviour among post-graduate university students in Durban, South Africa. Accident Analysis \& Prevention, 55, 6776. https://doi.org/10.1016/j.aap.2013.02.021

7. Boiadjieva, N. I. (2014). Empathy, emotional intelligence and personal profile of helping specialists for socio-pedagogical work. In S. Dzhonev, P. Dimitrov, \& N. Mateeva (Eds.), Sbornik nauchni dokladi ot sedmiya natsionalen congress po psihologia. Sofia, 31.1002.11.2014 [Proceedings of 7th national congress of Psychology. Sofia, 31.10-02.11.2014] (pp. 534-542). Sofia: LM LTD.

8. Convention on the Rights of the Child. (1990). Retrieved in October 2020, from www2.ohchr.org/English/law/pdf/crc.pdf

9. Cross, C. P., Cyrenne, D.-L. M., \& Brown, G. R. (2013). Sex differences in sensation-seeking: A meta-analysis. Scientific Reports, 3(1), 2486. https://doi.org/10.1038/srep02486 
10. Dervic, K., Garcia-Amador, M., Sudol, K., Freed, P., Brent, D. A., Mann, J. J., HarkavyFriedman, J. M., \& Oquendo, M. A. (2015). Bipolar I and II versus unipolar depression: Clinical differences and impulsivity/aggression traits. European Psychiatry, 30(1), 106-113.

11. Dickman, S. J. (1990). Functional and dysfunctional impulsivity: Personality and cognitive correlates. Journal of Personality and Social Psychology, 58(1), 95-102. https://doi.org/10.1037//0022-3514.58.1.95

12. Evren, C., \& Bozkurt, M. (2017). Impulsivity and opioid use disorder. Dusunen Adam: The Journal of Psychiatry and Neurological Sciences, 30, 75-78. https://doi.org/10.5350/DAJPN2017300211

13. Eysenck, H. (1987). Model za lichnost [Model of personality]. Sofia, Bulgaria: Nauka I izkustvo.

14. Fairchild, A. J., \& McQuillin, S. D. (2010). Evaluating mediation and moderation effects in school psychology: A presentation of methods and review of current practice. Journal of School Psychology, 48(1), 53-84. https://doi.org/10.1016/j.jsp.2009.09.001.

15. Faul, F., Erdfelder, E., Lang, A.-G., \& Buchner, A. (2007). G*Power 3: A flexible statistical power analysis program for the social, behavioral, and biomedical sciences. Behavior Research Methods, 39, 175-191.

16. Garza, K. B., Ding, M., Owensby, J. K., \& Zizza, C. A. (2016). Impulsivity and fast-food consumption: A cross-sectional study among working adults. Journal of the Academy of Nutrition \& Dietetics, 116(1), 61-68.

17. Giannouli, V., \& Stoyanova, S. (2019). Youth impulsivity in Southern Bulgaria. European Psychiatry, 56(Supplement 1 - Abstracts of 27th European Congress of Psychiatry, Warsaw, Poland, 6-9 April 2019; E-Poster Presentation: Child and Adolescent Psychiatry - Part II), S35, S49. E-PP0144. https://doi.org/10.1016/j.eurpsy.2019.01.003.

18. Glen, S. (2015). Statistical power: What it is, how to calculate it. From StatisticsHowTo.com: Elementary Statistics for the rest of us! https://www.statisticshowto.com/statistical-power/

19. Hair, J. F., Hult, G. T. M., Ringle, C. M., \& Sarstedt, M. (2016). A primer on partial least squares structural equation modeling (PLS-SEM). 2nd edition. Thousand Oaks, CA: Sage.

20. Hayes, A. F. (2017). Introduction to mediation, moderation, and conditional process analysis: A regression-based approach (2nd edition). New York: Guilford Press.

21. He, J., Van De Vijver, F. J. R., Espinosa, A. D., Abubakar, A., Dimitrova, R., Adams, B. G., Aydinli ,A., Atitsogbe, K., Alonso-Arbiol, I., Bobowik, M., Fischer, R., Jordanov, V., Mastrotheodoros, S., Neto, F., Ponizovsky, Y. J., Reb, J., Sim, S., Sovet, L., Stefenel, D., Suryani, A. O., Tair, E., \& Villieux, A. (2015). Socially desirable responding: Enhancement and denial in 20 countries. Cross-Cultural Research, 49(3), 227-249. https://doi.org/10.1177/1069397114552781

22. Horvath, P., \& Zuckerman, M. (1993). Sensation seeking, risk appraisal, and risky behavior. Personality and Individual Differences, 14(1), 41-52. https://doi.org/10.1016/01918869(93)90173-Z

23. Hosu, R.-I., \& Nastasa, L. E. (2008). Emotional intelligence and aggression. Buletinul Universitatii Petrol - Gaze din Ploiesti, Seria Stiintele Educatiei, LX(1B), 8 - 14.

24. IBM Corp. (2011). IBM SPSS Statistics for Windows, Version 20.0. Armonk, NY: IBM Corp. Retrieved from https://www.ibm.com/support/pages/how-cite-ibm-spss-statistics-or-earlierversions-spss

25. JASP Team. (2019). JASP (Version 0.11.1) [Computer software]. Retrieved from https://jaspstats.org/download/

26. Jung, J. (2017). Impact of motives on impulsivity and compulsivity in compulsive buying behavior. Social Behavior and Personality, 45(5), 705-718. https://doi.org/10.2224/sbp.5885

27. Kalchev, P. (2016). Otsenka na psihopatni cherti $v$ iunosheska vazrast [Assessment of psychopathic traits in adolescent age]. Sofia: Iztok-Zapad.

28. Kao, Y.-C., Liu, Y.-P., Cheng, T.-H., \& Chou, M.-K. (2011). Cigarette smoking in outpatients with chronic schizophrenia in Taiwan: Relationships to socio-demographic and clinical characteristics. Psychiatry Research, 190(2/3), 193-199.

29. Kasmaei, S. K., \& Asghari, F. (2017). Comparative study of the effects of narrative therapy and play therapy by group approach on inhibiting impulsivity, reducing aggression and increasing interpersonal relations. World Family Medicine/Middle East Journal of Family Medicine, 15(4), 24-33. 
30. Kazandzhieva, E. M. (2014). Influence of the locus of control as a matter of employment: personality and entrepreneurial behavior. In S. Dzhonev, P. Dimitrov, \& N. Mateeva (Eds.), Sbornik nauchni dokladi ot sedmiya natsionalen congress po psihologia. Sofia, 31.1002.11.2014 [Proceedings of 7th national congress of Psychology. Sofia, 31.10-02.11.2014] (pp. 864-868). Sofia: LM LTD.

31. Kumar, P., \& Singh, U. (2015). Zuckerman's alternative five factor model and risk taking behavior. The International Journal of Indian Psychology, 3(1), 6.

32. Leung, L. (2008). Leisure boredom, sensation seeking, self-esteem, addiction symptoms and patterns of cell phone use. In E. A. Konijn, M. A. Tanis, S. Utz, \& A. Linden (Eds.), Mediated interpersonal communication (pp. 359-381). Mahwah, NJ: Lawrence Erlbaum Associates.

33. Lynam, D. R. (n.d.). UPPS-P. Retrieved in December 2017, from https://goo.gl/8kNbw1

34. MacKinnon, D. P., Fairchild, A. J., \& Fritz, M. S. (2007). Mediation analysis. Annual review of psychology, 58, 593-614. https://doi.org/10.1146/annurev.psych.58.110405.085542

35. Maidaniuc-Chirila, T., \& Treadway, D. C. (2016). Longitudinal relationships between workplace bullying, passive coping strategies and strain: testing three crosslagged mediation models. Journal of Educational Sciences \& Psychology, 6(2), 58 - 70.

36. Manna, G., Faraci, P., \& Como, M. R. (2013). Factorial structure and psychometric properties of the Sensation Seeking Scale - Form V (SSS-V) in a sample of Italian adolescents. Europe's Journal of Psychology, 9(2), 276-288. https://doi.org/10.5964/ejop.v9i2.500

37. Manova, M. I. (2014). Psychotherapeutic treatment options for patients with a diagnosis "breast cancer". In S. Dzhonev, P. Dimitrov, \& N. Mateeva (Eds.), Sbornik nauchni dokladi ot sedmiya natsionalen congress po psihologia. Sofia, 31.10-02.11.2014 [Proceedings of 7th national congress of Psychology. Sofia, 31.10-02.11.2014] (pp. 1126-1131). Sofia: LM LTD.

38. Maraz, A., Andó, B., Rigó, P., Harmatta, J., Takách, G., Zalka, Z., Boncz, I., Lackó, Z., Urbán, R., van den Brink, W., \& Demetrovics, Z. (2016). The two-faceted nature of impulsivity in patients with borderline personality disorder and substance use disorder. Drug \& Alcohol Dependence, 163, 48-54.

39. Mihova, Z. M. (2014). Development of reflexive parenting for children with problem behavior. In S. Dzhonev, P. Dimitrov, \& N. Mateeva (Eds.), Sbornik nauchni dokladi ot sedmiya natsionalen congress po psihologia. Sofia, 31.10-02.11.2014 [Proceedings of 7th national congress of Psychology. Sofia, 31.10-02.11.2014] (pp. 1195-1205). Sofia: LM LTD.

40. Miller, D. J. (2007). The multifaceted nature of impulsive sensation-seeking: Differential relationships with personality, deviance, and laboratory tasks. University of Kentucky Master's Theses. 423. Retrieved in December 2017, from https://uknowledge.uky.edu/gradschool_theses/423

41. Netto, L. R., Pereira, J. L., Nogueira, J. F., Cavalcanti-Ribeiro, P., Santana, R. C., Teles, C. A., Koenen, K. C., \& Quarantini, L. (2016). Impulsivity is relevant for trauma exposure and PTSD symptoms in a non-clinical population. Psychiatry Research, 239, 204-211.

42. Nikolov, P., Georgiev, L., \& Madolev, V. (2007). Psihologiya na universitetskoto obutchenie [Psychology of university education]. Blagoevgrad, Bulgaria: South-West University "Neofit Rilski”.

43. Patton, J. H., Stanford, M. S., \& Barratt, E. S. (1995). Factor structure of the Barratt impulsiveness scale. Journal of Clinical Psychology, 51(6), 768-774.

44. Peters, E. M., Balbuena, L., Marwaha, S., Baetz, M., \& Bowen, R. (2016). Mood instability and impulsivity as trait predictors of suicidal thoughts. Psychology and Psychotherapy: Theory, Research and Practice, 89, 435-444.

45. Pitts, S. R., \& Leventhal, A. M. (2012). Associations of functional and dysfunctional impulsivity to smoking characteristics. Journal of Addicting Medicine, 6(3), 226-232. https://doi.org/ 10.1097/ADM.0b013e31825e2a67

46. Popov, V., Psederska, E., Peneva, E., Bozgunov, K., Vasilev, G., Nedelchev, D., \& Vassileva, J. (2016). Psychometric characteristics of the Bulgarian version of the Toronto Alexithymia Scale (TAS-20). Psychological Research, 19(2), 25-42.

47. Preacher, K. J., \& Leonardelli, G. J. (2001). Calculation for the Sobel test: An interactive calculation tool for mediation tests. Retrieved in October 2020, from http://quantpsy.org/sobel/sobel.htm

48. Radoslavova, M., \& Velichkov, A. (2005). Metodi za psihodiagnostika [Methods for psychodiagnostics]. Sofia: Pandora prim. 
49. Raine, A., Reynolds, C., Venables, P. H., Mednick, S. A., \& Farrington, D. P. (1998). Fearlessness, stimulation-seeking, and large body size at age 3 years as early predispositions to childhood aggression at age 11 years. Archives of General Psychiatry, 55, 745-751.

50. Reas, D. L., Pedersen, G., \& Rø, Ø. (2016). Impulsivity-related traits distinguish women with co-occurring bulimia nervosa in a psychiatric sample. International Journal of Eating Disorders, 49(12), 1093-1096. https://doi.org/10.1002/eat.22606.

51. Schalling, D., \& Åsberg, M. (1985). Biological and psychological correlates of impulsiveness and monotony avoidance. In J. Strelau, F. H. Farley, \& A. Gale (Eds.), The series in clinical and community psychology. The biological bases of personality and behavior. Vol. 1. Theories, measurement techniques and development (pp. 181-194). New York: Hemisphererp/Harper \& Row.

52. Slavchov, B., \& Virmozelova, N. (2007). Osobenosti na vremevata orientatsia na studentite i izbora im na spetsialnost [Peculierities of students' time-orientation and their choice of specialty]. Bulgarian journal of psychology, 3, 322-330.

53. Steele, C. C., Pirkle, J. R. A., \& Kirkpatrick, K. (2017). Diet-induced impulsivity: Effects of a high-fat and a high-sugar diet on impulsive choice in rats. PLoS ONE, 12(6), e0180510. https://doi.org/10.1371/journal.pone.0180510

54. Stoyanova, S. (2020). Functional, dysfunctional impulsivity and sensation seeking. Mendeley Data, V1, doi: 10.17632/4d6k8knnp6.1

55. Stoyanova, S., \& Giannouli, V. (2018). Bulgarian students' impulsivity differentiated by gender, age, and some scientific areas. Psychological Thought, 11(2), 138-147. http://dx.doi.org/10.5964/psyct.v11i2.250

56. Stoyanova, S., \& Ivantchev, N. (2021). Associations among functional and dysfunctional impulsivity: Direct and indirect effects on sensation seeking in youth (19-25 years old). Psychological Thought, 14(1), 1-37.

57. Tamam, L., Paltaci, Ö., \& Keskin, N. (2017). Prevalence and characteristics of impulse control disorders in a group of medical students. Anatolian Journal of Psychiatry / Anadolu Psikiyatri Dergisi, 18(2), 113-120.

58. Taneva, T. (2012). Tarsene na useshtania I subektivna pertseptsia na riska [Sensation seeking and subjective risk perception]. Science \& Technologies, 2(8), 145-153.

59. Wang, L., Tao, T., Fan, C., Gao, W., \& Wei, C. (2017). The association between Internet addiction and both impulsivity and effortful control and its variation with age. Addiction Research \& Theory, 25(1), 83-90.

60. Whiteside, S. P., \& D. R. Lynam (2001). The Five Factor Model and impulsivity: Using a structural model of personality to understand impulsivity. Personality and Individual Differences, 30(4), 669-689.

61. Yıldız, F., \& Gündüz, B. (2020). An investigation of the mediator role of emotional regulation in the relationship between cognitive flexibility and psychological symptoms in adolescents. Journal of Educational Sciences \& Psychology, 10(2), 133 - 146.

62. Zadravec, T., Bucik, V., \& Sočan, G. (2005). The place of dysfunctional and functional impulsivity in the personality structure. Horizons of Psychology, 14(2), 39-50.

63. Zarbova, B. P. (2019). Stres i blagopoluchie vav visokoriskova sreda [Stress and well-being in high-risk environment]. Abstract of PhD thesis. Sofia: Sofia University "St. Kliment Ohridski”.

64. Zhao, J., Tomasi, D., Wiers, C. E., Shokri-Kojori, E., Demiral, Ş. B., Zhang, Y., Volkow, N. D., \& Wang, G.-J. (2017). Correlation between traits of emotion-based impulsivity and intrinsic default-mode network activity. Hindawi Neural Plasticity, 2017, Article ID 9297621, https://doi.org/10.1155/2017/9297621

65. Zuckerman, M. (2005). Psychobiology of personality. Cambridge: Cambridge University Press.

66. Zuckerman, M. (2007). The Sensation Seeking Scale V (SSS-V): Still reliable and valid. Personality and Individual Differences, 43, 1303-1305.

67. Zuckerman, M., Kolin, E. A., Price, L., \& Zoob, I. (1964). Development of a sensation-seeking scale. Journal of Consulting Psychology, 28(6), 477-482. http://dx.doi.org/10.1037/h0040995 